\title{
Eastward Shift of Northwest Pacific Tropical Cyclone Genesis Frequency Anomaly in Decaying El Niño
}

\author{
Yao HA \\ College of Meteorology and Oceanography, PLA University of Science and Technology, Nanjing, China \\ Zhong ZHONG \\ College of Meteorology and Oceanography, PLA University of Science and Technology, Nanjing, China \\ ICGCR, School of Atmospheric Sciences, Nanjing University, Nanjing, China \\ and \\ Xiuqun YANG \\ ICGCR, School of Atmospheric Sciences, Nanjing University, Nanjing, China
}

(Manuscript received 24 May 2012, in final form 14 May 2013)

\begin{abstract}
This study focuses on longitudinal evolution of tropical cyclone genesis frequency (TCGF) anomaly over the western North Pacific (WNP) from July to October in the El Niño decaying (EDC) years and its possible mechanisms. Results show that TCGF anomaly exhibits a dipole pattern with a negative center in the eastern WNP and a positive center in the western WNP. In particular, the mean position of negative (positive) anomaly shifts eastward from $130^{\circ} \mathrm{E}$ $\left(120^{\circ} \mathrm{E}\right)$ in July to $160^{\circ} \mathrm{E}\left(145^{\circ} \mathrm{E}\right)$ in October. Moreover, the evolving feature of negative TCGF anomaly is exhibited more clearly. This evolution of TCGF anomaly largely determines the distribution of climatological TC kinetic energy anomaly, which also shifts eastward and persists throughout the EDC fall. Tropical Indian Ocean warming and equatorial central eastern Pacific cooling jointly modulates the large-scale atmospheric circulation and environmental conditions over the WNP, contributing to the eastward shift of TCGF anomaly during the EDC summer and fall. A better understanding of the evolution of TCGF anomaly could be beneficial for the improvement of the seasonal TC prediction over the individual regions over the WNP for the EDC years.
\end{abstract}

Keywords tropical cyclone; ENSO; East Asian monsoon

\section{Introduction}

El Niño-Southern Oscillation (ENSO) is regarded as one of the most important factors to modulate the East Asian climate as well as tropical cyclone (TC) activity

Corresponding author: Zhong Zhong, College of Meteorology and Oceanography, PLA University of Science and Technology, No. 60 Shuanglong Road, Zhong Hua Men Wai, Nanjing 211101, China

E-mail: zhong_zhong@yeah.net

C2013, Meteorological Society of Japan in the western North Pacific (WNP) (Ju and Slingo 1995; Chang et al. 2000a, b; Wang and Chan 2002; Zhao et al. 2011). Most previous studies focused on the influence of different ENSO phases on the interannual variability of WNP TC genesis location, frequency, track, intensity, and life span (Chan 2000; Chia and Ropelewski 2002; Wang and Chan 2002; Camargo and Sobel 2005; Chen et al. 2006; Zhao et al. 2010; He and Jiang 2011; Zhan et al. 2011a; Ha and Zhong 2013; Ha et al. 2013), which exhibits distinct spatiotemporal characteristics corresponding to different ENSO 
phases. For example, TC activity in the southeastern (northwestern) WNP has a higher (lower) genesis frequency, stronger (weaker) intensity, and longer (shorter) life span in El Niño, and the opposite features appear in La Niña. More recently, it is revealed that the sea surface temperature (SST) gradient between the southwestern Pacific and the western Pacific warm pool in boreal spring is a crucial factor to modulate the interannual variability of WNP TC activity (Zhan et al. 2013). In addition, the WNP TC activity is strongly modulated by the activity of the East Asian summer monsoon (Lander 1994; Chen et al. 2006; Wu et al. 2011), which exhibits different variabilities on various time scales and complicated spatial structures (Chang et al. 2000a, b; Zhou and Yu 2005; Yu and Zhou 2007; Zhou et al. 2009). It has been found that two dominant modes exist in the interannual variability of the East Asian climate, El Niño developing (EDV) and El Niño decaying (EDC) modes, corresponding to El Niño summer and fall and those following the previous El Niño year, respectively ( $\mathrm{Wu}$ et al. 2009). The atmospheric circulation anomalies in the two modes show distinct features from summer to the subsequent fall, and the different environmental conditions exert distinct impacts on the synoptic-scale disturbances over the WNP, including TC activities. Many studies focus on the WNP TC activity in the EDV mode (Chan 2000; Chia and Ropelewski 2002; Wang and Chan 2002; Camargo and Sobel 2005; Zhan et al. 2011a), while recent studies reveal an obvious negative correlation between the WNP TC frequency and SST anomaly (SSTA) in the tropical Indian Ocean (TIO; Du et al. 2011; Zhan et al. 2011a, b; Tao et al. 2012). In particular, warm TIO SSTA forces an equatorial baroclinic Kelvin wave in the lower troposphere, propagating to the tropical Pacific, which strongly impacts the WNP anomalous anticyclonic circulation and further suppresses the WNP TC activity in the EDC summer and fall (Xie et al. 2009; Du et al. 2011).

Although TC activity are suppressed over the entire WNP in the EDC summer, some issues about the anomaly of TC genesis frequency (TCGF) in the EDC mode need further investigate in detail: (1) The enhanced low-level anticyclonic circulation dominates the WNP during the EDC summer (Wang et al. 2000; Xie et al. 2009), which remarkably affects the WNP TC genesis. Previous studies examined the influence of WNP anomalous circulation on TC activity by the composite analysis from July to September (Du et al. 2011) or June to October (Zhan et al. 2011a) as a whole. However, the WNP anomalous anticyclone exhibits evolving features in location and strength from spring to the subsequent fall of EDC years, thus does the anomaly of WNP TCGF show the seasonal evolution in response to the change of anomalous anticyclone during the EDC summer and the subsequent fall? (2) What is the influence of TCGF anomaly on the distribution of TC intensity represented by TC kinetic energy (TCKE) in summer and the subsequent fall? (3) Although it is well known that TC activity shows a dipole pattern with enhanced (reduced) cyclogenesis over the southeastern (northwestern) WNP in EDV years, does TCGF anomaly exhibit similar evolving features as that in EDC years? To address the above issues, we examine the anomalous features of the WNP TCGF in the EDC mode; the influences of the corresponding large-scale circulation and environmental conditions on the TCGF anomaly are also illustrated.

This paper is organized as follows: datasets and methodology are described in Section 2. Characteristics of the WNP TC genesis anomaly and its influence on the distribution of climatological TCKE in the EDC mode are presented in Section 3. Large-scale circulation and environmental conditions associated with the evolution of cyclogenesis anomaly are discussed in Section 4. Conclusions and discussion are presented in Section 5.

\section{Data and methodology}

TC best-track dataset is employed to determine the anomaly of TCGF during TC peak seasons from July to October (JASO) from 1979 to 2010, which is provided by the Regional Specialized Meteorological Center (RSMC) of Japan Meteorological Agency (JMA 2012) at 6-h intervals. The dataset, including satellite data after the 1970s, provides great advantage to locate the TCs, and the present study only focuses on those TCs that reach tropical storm intensity (10-min average maximum sustained wind speed $\geq 17 \mathrm{~m} \mathrm{~s}^{-1}$ ) based on the JMA scale. To calculate the TCGF, each TC genesis position is binned into its corresponding $5^{\circ} \times$ $5^{\circ}$ grid box. The extended reconstructed SST (ERSST; Smith et al. 2008) and monthly Niño-3.4 index are obtained from the National Oceanic and Atmospheric Administration (NOAA). Zonal and meridional wind fields with a spatial resolution of $2.5^{\circ} \times 2.5^{\circ}$ and a temporal resolution of four times per day as well as sea-level pressure (SLP) data are extracted from the National Centers for Environmental Prediction-National Center for Atmospheric Research Reanalysis Project Dataset (NNRP I; Kalnay et al. 1996).

Composite analysis method is applied in this study, and the two-tailed Student's $t$-test at $95 \%$ confidence 
level is used to examine the statistical significance of the composite analysis. There are nine EDV events based on the threshold of one standard deviation from the monthly Niño-3.4 index averaged from November to the subsequent January from 1979 to 2010, and eight EDC years are found following the EDV years because the consecutive years, 1986 and 1987, were strong El Niño years. Thus, the nine EDV years are 1982, 1986, 1987, 1991, 1994, 1997, 2002, 2006, and 2009, and the eight EDC years are 1983, 1988, 1992, 1995, 1998, 2003, 2007, and 2010.

Hsu et al. (2008) demonstrates that the TC wind field separated from the reanalysis data can represent the interseasonal variation of the WNP TC intensity for TC climatology studies. To clearly present the evolution of the WNP TC intensity anomaly in the EDC mode, $850-\mathrm{hPa}$ horizontal TC wind field is retrieved from the reanalysis data by means of the TC bogus technique provided by the fifth-generation Pennsylvania State University-NCAR Mesoscale Model (MM5) based on the TC best-track dataset. After locating first-guess vortex area and decomposing reanalysis wind field, TC wind component can be derived by the sum of velocity potential and nondivergent winds. More details of the method can be found in Low-Nam and Davis (2001).

To examine the contribution of environmental fields to TC genesis, genesis potential index (GPI) is calculated following Emanuel and Nolan (2004). The index is defined as GPI $=\left|10^{5} \eta\right|^{\frac{3}{2}}(H / 50)^{3}\left(V_{\text {pot }} / 70\right)^{3}(1+$ $\left.0.1 V_{\text {shear }}\right)^{-2}$, where $\eta$ is the absolute vorticity at 850 $\mathrm{hPa}, H$ is the relative humidity at $600-\mathrm{hPa}, V_{\text {pot }}$ is the potential intensity, and $V_{\text {shear }}$ is the magnitude of the vertical wind shear between $200-\mathrm{hPa}$ and $850-\mathrm{hPa}$. It is found that the seasonal variation and spatial distribution of the calculated GPI are consistent with those of Camargo et al. (2007), which are considered acceptable (not shown). It should be pointed out that, although the calculated GPI with the reanalysis wind field can present the effect of large-scale circulation on TC genesis, the TC wind field itself is still included in the background circulation during TC peak seasons, thus with an excessive positive vorticity in the domain of TC activity. Moreover, the TC activity in the WNP can impact the variability of East Asian summer climate (Wu et al. 2005; Zhong and Hu 2007; Hsu et al. 2008) as well as the GPI calculation to some extent. Therefore, to accurately reflect the contribution of background circulation to the WNP TC genesis, GPI was calculated with the TC-removed reanalysis wind field using the bogus technique.

\section{TCGF anomaly in the EDC mode}

Figure 1 shows the composite monthly TCGF anomaly from July to October in the EDC mode. It can be seen that the decreased TCGF is the dominant characteristic over JASO. That is, there are 17.9 TCs annually over JASO, while 16.2 TCs formed over JASO of EDC years, which is less than the climatological mean by 1.7 . In particular, the monthly TCGF from July to September is also less than the respective monthly climatological mean, which are labeled in the top-left corner of each panel in Fig. 1. This agrees well with recent studies (Du et al. 2011; Zhan et al. 2011a; Tao et al. 2012) stating that the WNP TC activity is suppressed in summer following strong El Niño events. However, TCs in October is slightly higher than the climatological mean by 0.9 (Fig. 1d), indicating that interseasonal variation of the WNP TCGF exists between the EDC summer and the subsequent fall. Moreover, the TCGF anomaly exhibits a dipole pattern with a positive (negative) center over the western (eastern) WNP, persisting from August to October (Figs. 1b-d), which shows the opposite phase relative to that in the EDV mode provided by Chia and Ropelewski (2002) and Wang and Chan (2002). To clearly illustrate the longitudinal evolution feature of TCGF over JASO, the composite time-longitude cross sections of climatological mean and anomalous TCGF in the EDC mode are shown in Fig. 2, which were calculated with 10-day mean TCGF over JASO during 1979-2010. The mean longitude of TCGF anomaly averaged between $0^{\circ}$ and $40^{\circ} \mathrm{N}$ is marked in the cross sections. It is represented by the barycentre from $100^{\circ} \mathrm{E}$ to $170^{\circ} \mathrm{W}$ with the expression of $\sum_{i=1}^{i=n} f r e_{i} l_{o n} / \sum_{i=1}^{i=n} f r e_{i}$, where fre $_{i}$ is the positive or negative TCGF anomaly, $\operatorname{lon}_{i}$ is the longitude corresponding to fre $_{i}$, and $i=1$ to $n$ indicates integrating from $100^{\circ} \mathrm{E}$ to $170^{\circ} \mathrm{W}$ over the WNP. It is shown that the climatological location of TCGF shifts eastward from mid-summer to fall, especially, with the mean position moving from $130^{\circ} \mathrm{E}$ in July to $150^{\circ} \mathrm{E}$ in late October (Fig. 2a), which is consistent with that of Lander (1994) and Ho et al. (2004), suggesting that the atmospheric circulation could hasten the eastward march of main TC genesis locations. Compared to the shift of climatological TCGF, the significant TCGF anomaly in the EDC mode also exhibits eastward march over JASO, as shown in Fig. 2b. It can be seen that the positive (negative) TCGF anomaly in the western (eastern) WNP shows a longitudinal march from July to October. In particular, the barycentre of negative TCGF anomaly propagates eastward from 

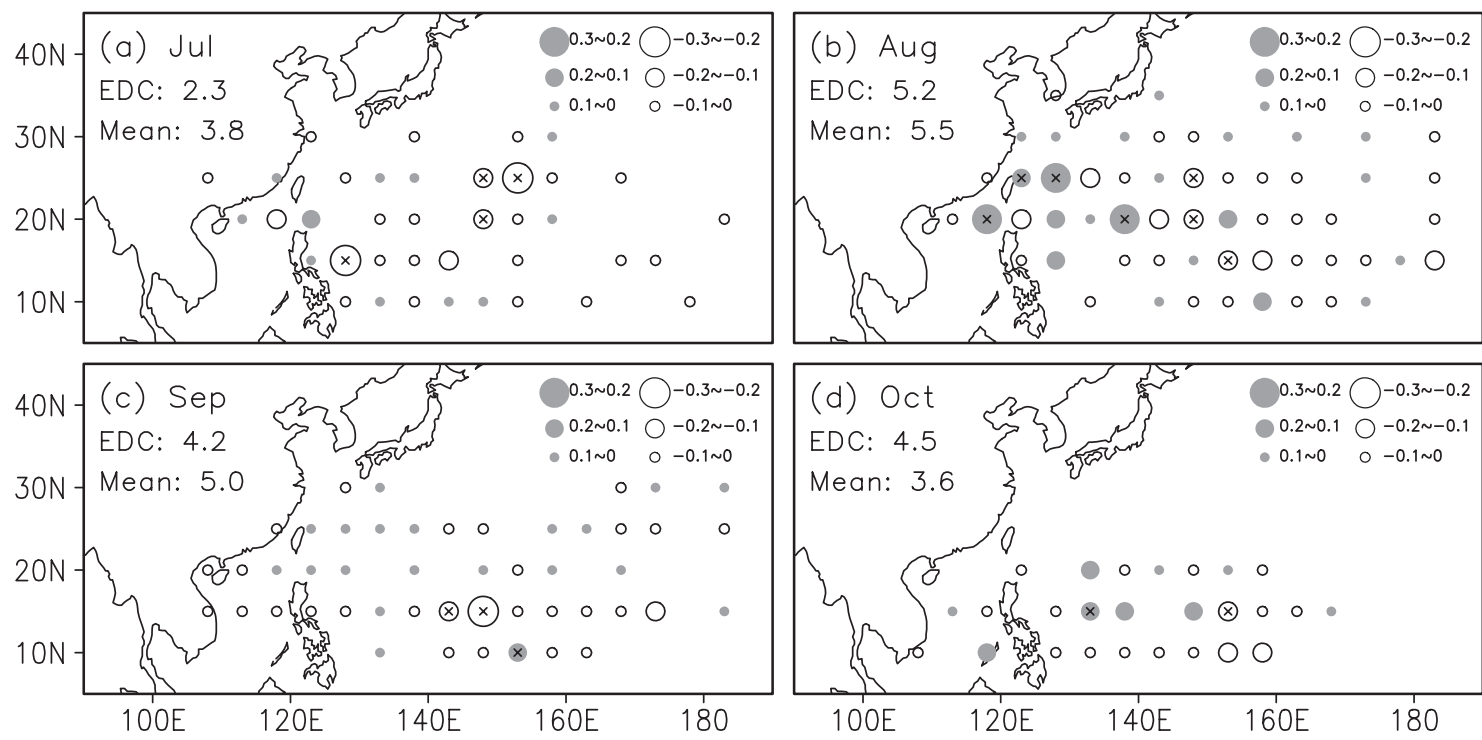

Fig. 1. Composite TCGF anomaly in (a) July, (b) August, (c) September, and (d) October in the EDC mode during 19792010. Circles with crosses are significant at the $95 \%$ confidence level by the Student's $t$-test, and the numbers in the topleft corner of each panel represent monthly TCGF and respective climatological mean from 1979 to 2010.

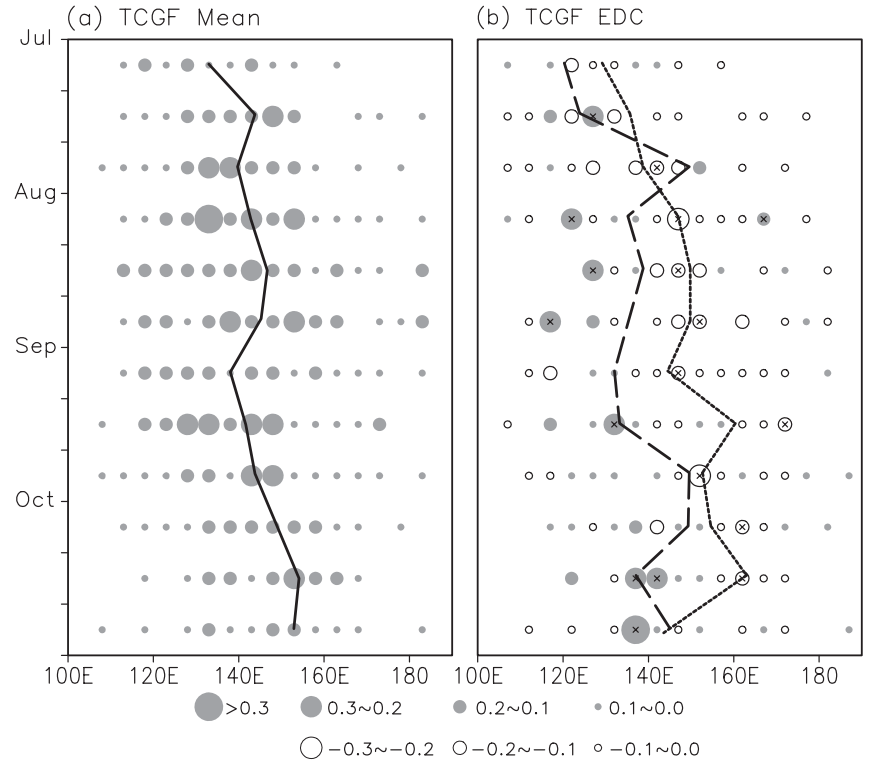

Fig. 2. Composite time-longitude cross section of (a) climatological mean TCGF and (b) TCGF anomaly in the EDC mode averaged between $0^{\circ}$ and $40^{\circ} \mathrm{N}$. Solid line in (a) and long (short) dashed line in (b) indicate mean longitudes of TCGF and positive (negative) TCGF anomaly, respectively. Circles with crosses in (b) are significant at the 95\% confidence level by the Student's $t$-test. 

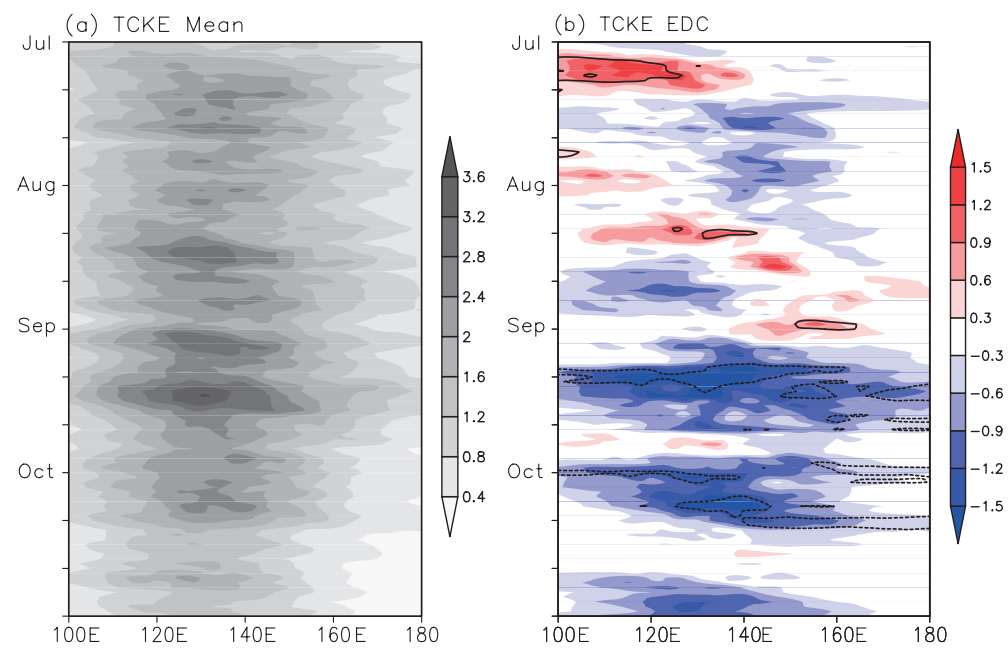

Fig. 3. Composite time-longitude cross section of (a) climatological mean TCKE (shade; $\mathrm{m}^{2} \mathrm{~s}^{-2}$ ) and (b) TCKE anomaly (shade; $\mathrm{m}^{2} \mathrm{~s}^{-2}$ ) in the EDC mode averaged between $0^{\circ}$ and $40^{\circ} \mathrm{N}$. Regions enclosed by solid (dashed) contours in (b) indicate areas where the positive (negative) differences are significant at the $95 \%$ confidence level by the Student's $t$-test.

$130^{\circ} \mathrm{E}$ in July to $160^{\circ} \mathrm{E}$ in mid-October. Meanwhile, the positive center also exhibits a similar evolution from $120^{\circ} \mathrm{E}$ in July to $145^{\circ} \mathrm{E}$ in October. In general, an anomalous TCGF dipole pattern shifts eastward from July to October continuously. Furthermore, the negative TCGF anomaly exhibits a clearer evolving feature relative to the positive TCGF anomaly in the EDC mode. It should be noted that the evolution of negative (positive) TCGF anomaly in the EDC mode apparently differs from that of climatological TCGF over JASO, because the former is modulated by the anomalous atmospheric circulation and environmental conditions over the WNP in the EDC years.

The location of TC genesis has a significant impact on TC intensity and life span (Walsh and Ryan 2000; $\mathrm{Wu}$ 2007). To examine the influence of TCGF anomaly on the TC intensity over JASO in the EDC mode, the horizontal TC wind field at $850-\mathrm{hPa}$ is separated from the reanalysis data by using TC vortices removed technique (Low-Nam and Davis 2001) based on the TC best-track dataset at each time. Then, the retrieved TC wind field is used to calculate TCKE, which can represent the spatiotemporal distribution of TC intensity. Figure 3 shows the composite time-longitude cross sections of climatological mean and anomalous TCKE in the EDC mode averaged between $0^{\circ}$ and $40^{\circ} \mathrm{N}$. Climatologically, the TCKE is centered at approximately $130^{\circ} \mathrm{E}$ and persists from mid-August to early October, with the maximum TCKE appearing in September (Fig. 3a). In the EDC summer, the negative TCKE anomaly is located in the east of the positive, and both negative and positive TCKE anomalies shift eastward, which is greatly attributed to the eastward march of TCGF anomalies. During the subsequent fall, the significant negative TCKE anomaly dominates the entire WNP, indicating that a distinct interseasonal variation of TC intensity exists between summer and fall in the EDC mode. The uniform negative anomaly of TC intensity over the WNP in the EDC fall might be attributed to two factors. On one hand, the signal of climatological TCKE reaches its maximum in mid-September, as shown in Fig. 3a. However, the suppressed TC activity is observed over the entire WNP in the EDC fall (Fig. 1c), which leads to the significant negative TCKE anomaly at that time. In addition, less TCs form in the eastern WNP in the EDC fall relative to those in August, and it is quite possible that significantly less TCs can reach the intensity of typhoon or intense typhoon in their life spans. Compared with the cyclogenesis in the eastern WNP, TCs formed in the western WNP have few chances to intensify and develop continuously as moving northward and westward over the WNP. Therefore, the results comprehensively exhibit extensive negative TCKE anomaly in the EDC fall (Fig. 3b). In particular, it is noteworthy that the significant negative anomaly exhibits an eastward shift in mid-September and early October (Fig. 3b), further indicating that the distribution of anomalous TC intensity may be affected by the 

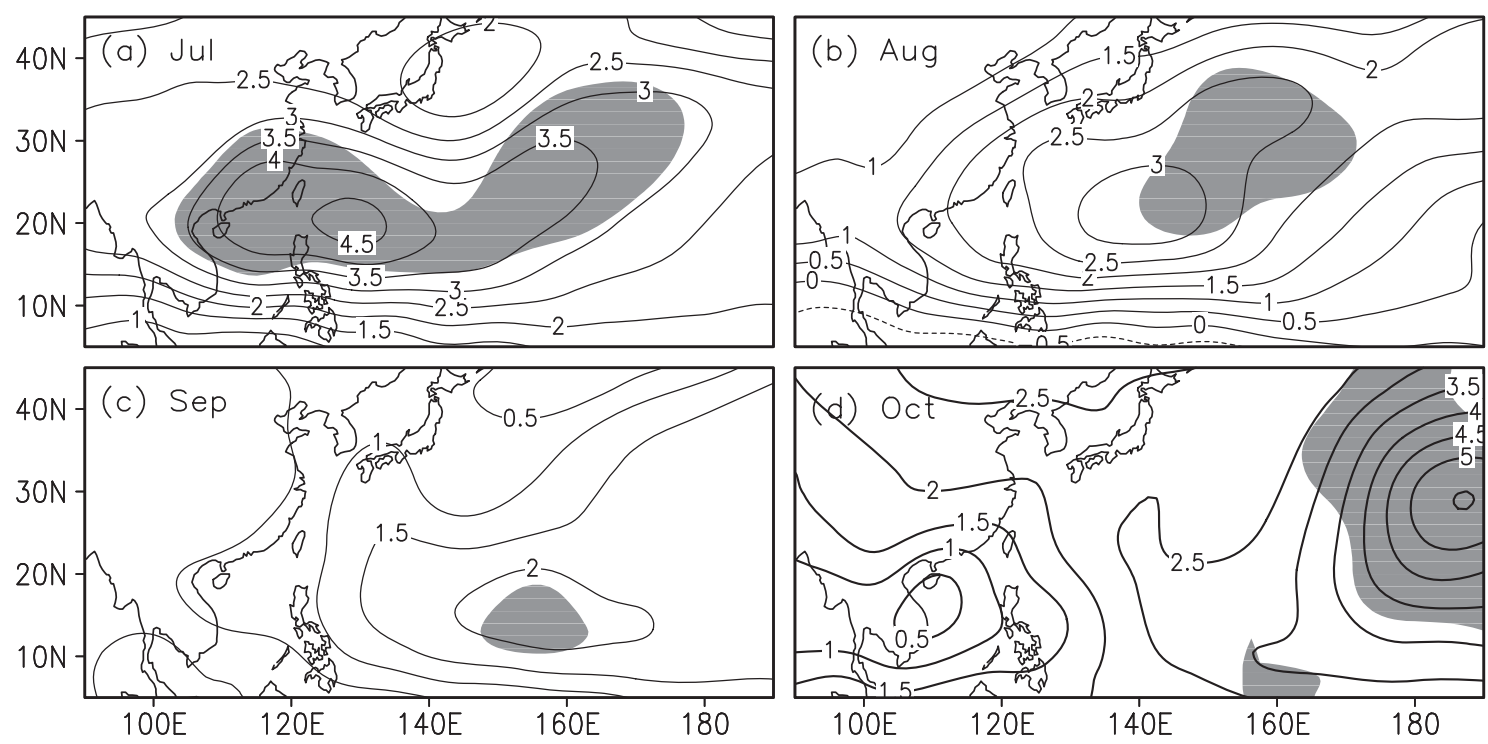

Fig. 4. Composite streamfunction anomaly (contours at interval $0.5 ; 10^{6} \mathrm{~m}^{2} \mathrm{~s}^{-1}$ ) at $850-\mathrm{hPa}$ in (a) July, (b) August, (c) September, and (d) October in the EDC mode. Shades indicate areas where the differences are significant at the $95 \%$ confidence level by the Student's $t$-test.

longitudinal evolution of TCGF anomaly.

\section{Large-scale circulation and GPI in the EDC mode}

The evolution of TCGF anomaly in the EDC mode is mainly modulated by the WNP anomalous anticyclone, which is closely related to the remote TIO warming and the cold equatorial central eastern Pacific SSTA (Klein et al. 1999; Yang et al. 2007). In summer, the WNP anomalous anticyclonic circulation dominates the entire WNP, suppressing the convection and reducing the TC frequency. In addition, the contribution of the remote TIO warming to the WNP anomalous anticyclone gradually intensifies during the EDC summer (Wu et al. 2010), indicating that the TIO SSTA plays an important role in modulating the WNP TC activity. In the subsequent fall, the WNP anomalous anticyclone becomes weak, due to the dissipation of warm TIO SSTA; meanwhile, TC genesis in the western WNP and the SCS would be enhanced. In contrast, the equatorial central eastern Pacific cooling exerts the persistent influence on suppressing TC activity in the eastern WNP. To examine the contribution of large-scale anomalous circulation to the evolution of TCGF anomaly, the tropospheric circulations in the EDC mode are presented in this section. Figure 4 shows the composite monthly streamfunction anomaly at $850-\mathrm{hPa}$ in the
EDC mode. An anomalous anticyclone over the western WNP is observed in the early summer, accompanying an enhanced easterly anomaly over the Maritime Continent (not shown). In July, easterly anomaly extends westward to the Bay of Bengal, and the anomalous anticyclone centered at $20^{\circ} \mathrm{N}, 130^{\circ} \mathrm{E}$ strengthens rapidly (Fig. 4a), where the suppressed TC genesis is also located (Fig. 1a). In August, the anomalous anticyclone shifts eastward centered around $20^{\circ} \mathrm{N}$, $140^{\circ} \mathrm{E}$ and weakens slightly (Fig. 4b), corresponding to the eastward march of the negative TCGF anomaly. The anomalous anticyclone further weakens and shifts eastward to approximately $18^{\circ} \mathrm{N}, 160^{\circ} \mathrm{E}$ in September (Fig. 4c), and the area of anomalous suppressed TC activity exhibits a similar variation. Meanwhile, enhanced convection and high moisture induced by the local air-sea interaction occurs over the SCS and the western WNP in the subsequent fall (not shown), which are favorable for TC genesis. In October, the anomalous anticyclone enhances and shifts eastward to the central Pacific (Fig. 4d), which propagates the negative TCGF anomaly further eastward. Corresponding to the anomalous circulation in the lower troposphere, the circulation anomaly in the upper troposphere exhibits a similar feature in the EDC mode. Figure 5 shows the evolution of monthly velocity potential anomaly at $200-\mathrm{hPa}$. It can be seen that the zero contour of velocity potential anomaly 

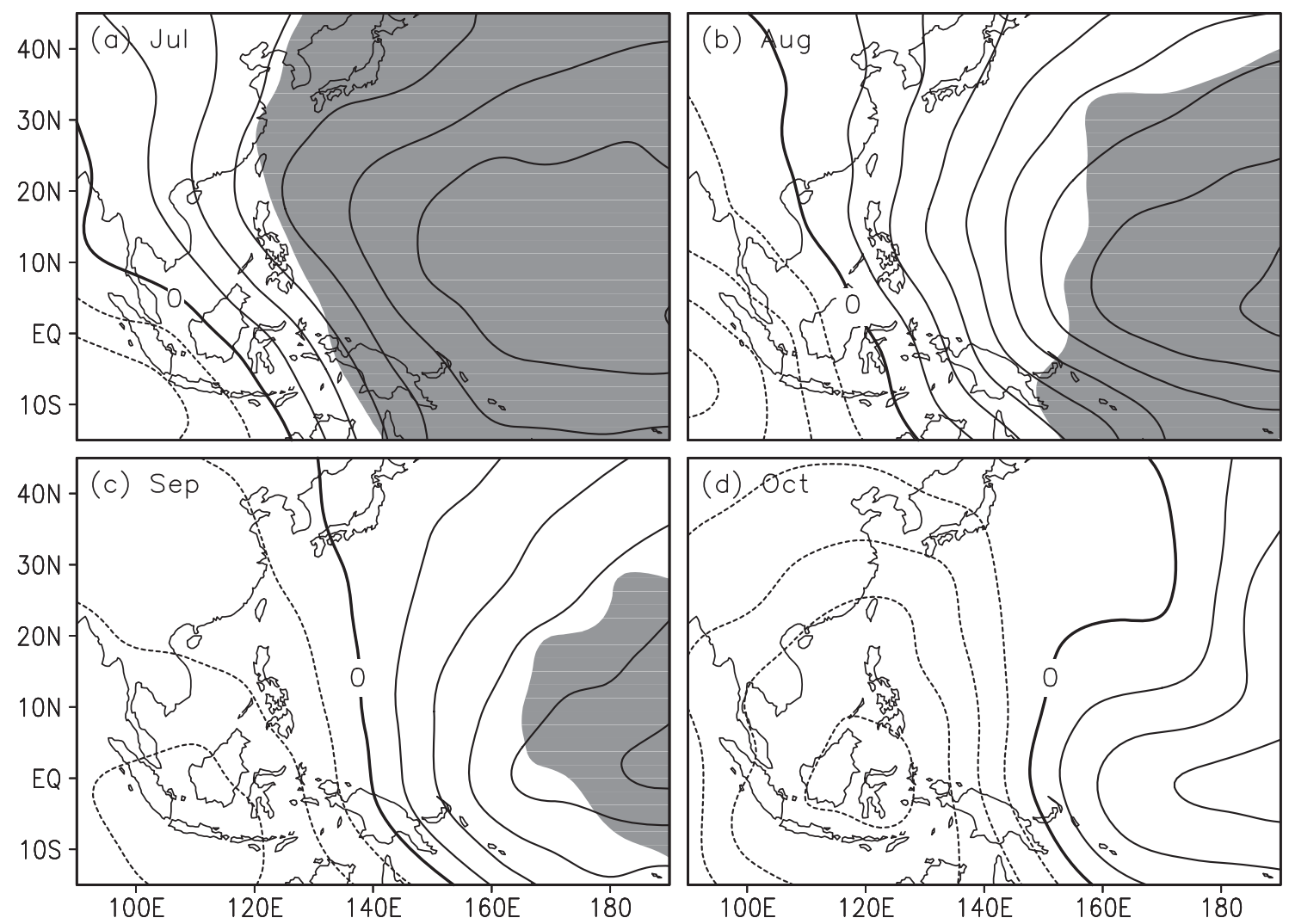

Fig. 5. Composite velocity potential anomaly (contours at interval $0.5 ; 10^{6} \mathrm{~m}^{2} \mathrm{~s}^{-1}$ ) at 200-hPa in (a) July, (b) August, (c) September, and (d) October in the EDC mode. Solid and dashed lines denote positive and negative values, respectively, and thick solid contours represent zero contour. Shades indicate areas where the differences are significant at the $95 \%$ confidence level by the Student's $t$-test.

shifts eastward from near $120^{\circ} \mathrm{E}$ in July to $160^{\circ} \mathrm{E}$ in October, suggesting that the anomalous Walker circulation moves eastward in the EDC mode. Therefore, the anomalous descending (ascending) motion in the eastern (western) WNP exhibits obvious evolving features, causing significant eastward propagation of negative (positive) TCGF anomaly in the EDC summer and fall. To better investigate the combined influences of equatorial central eastern Pacific cooling and the TIO warming on the evolution features of the large-scale circulation in the lower troposphere, correlations of monthly SLP from July to October with the normalized Niño-3.4 index and the TIO SSTA index averaged over JASO are shown in Fig. 6. The changes in SLP can reflect the strength variation of lower circulation greatly (Wang and Zhang 2002; Yuan et al. 2012). It is shown that the significant positive correlation between monthly SLP and Niño3.4 index intensifies and shifts eastward from July to
October, and the negative correlation slightly moves eastward as well (Figs. 6a-d). On the other hand, the positive correlation between monthly SLP and the TIO SSTA index also exhibits a similar feature, shifting eastward from $120^{\circ} \mathrm{E}$ in July to approximately $180^{\circ} \mathrm{E}$ in October (Figs. 6e-h). These results indicate that cold central eastern Pacific and warm TIO SSTAs make combined contributions to the anomalous eastward movement of large-scale circulation over the WNP during the EDC summer and fall, which further induces the longitudinal evolution of WNP TCGF anomalies.

GPI is an empirical index to assess climatological TC genesis conditions, which can be diagnosed from the reanalysis and model data (Emanuel and Nolan 2004; Camargo et al. 2007; Walsh et al. 2007). In this section, the GPI proposed by Emanuel and Nolan (2004) is calculated over the WNP in the EDC mode to detect the combined effect of climatic factors on TC 
(a) Corr (Jul SLP \& Nino-3.4)

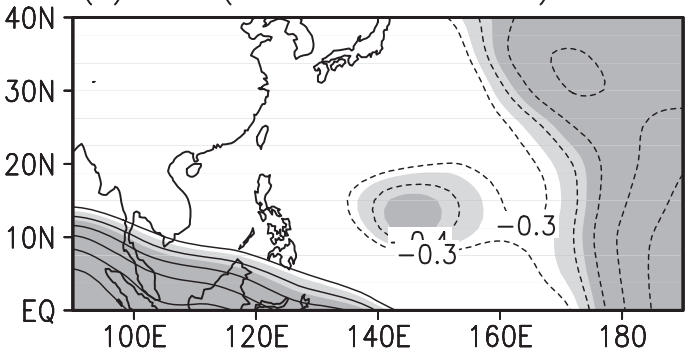

(b) Corr (Aug SLP \& Nino-3.4)

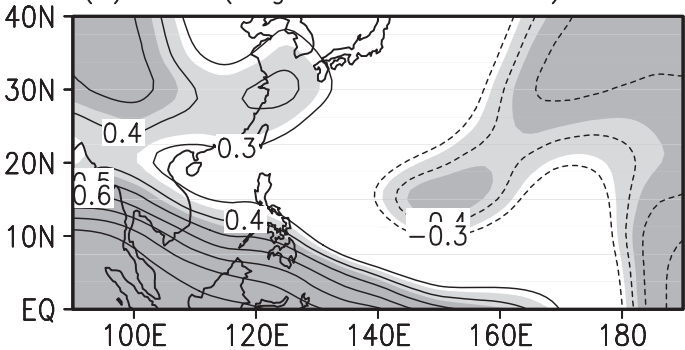

(c) Corr (Sep SLP \& Nino-3.4)

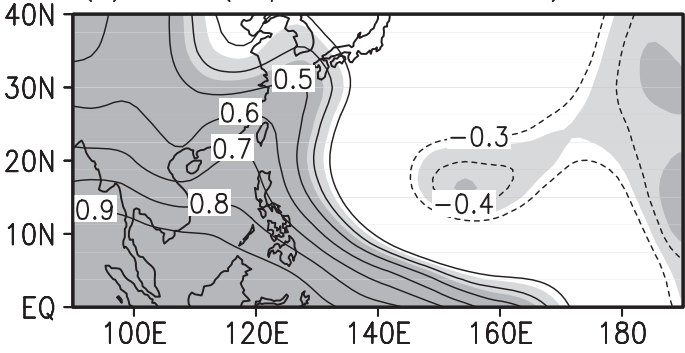

(d) Corr (Oct SLP \& Nino-3.4)

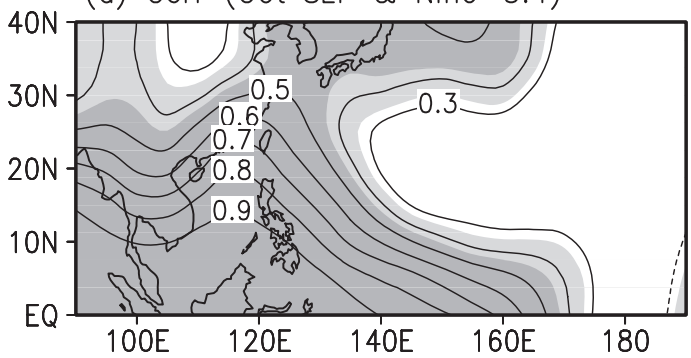

(e) Corr (Jul SLP \& TIO SSTA)

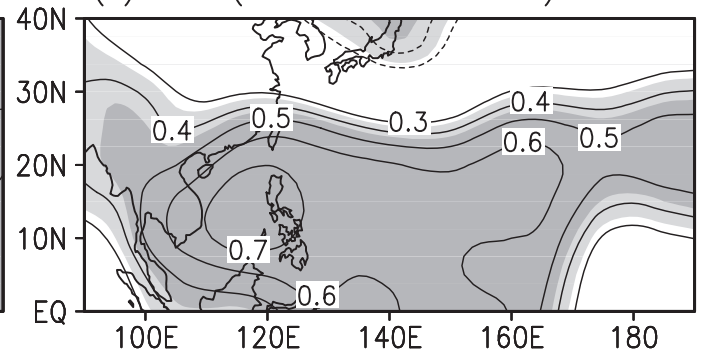

(f) Corr (Aug SLP \& TIO SSTA)

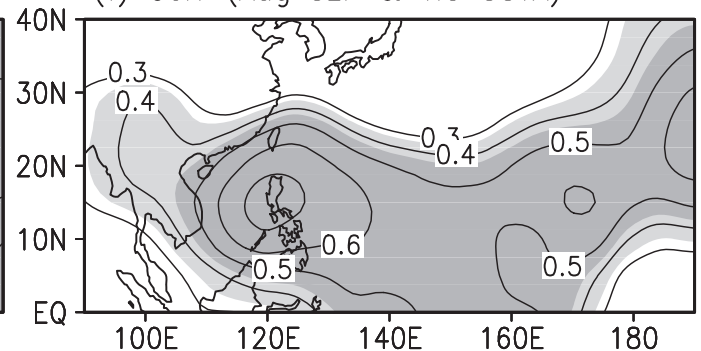

(g) Corr (Sep SLP \& TIO SSTA)

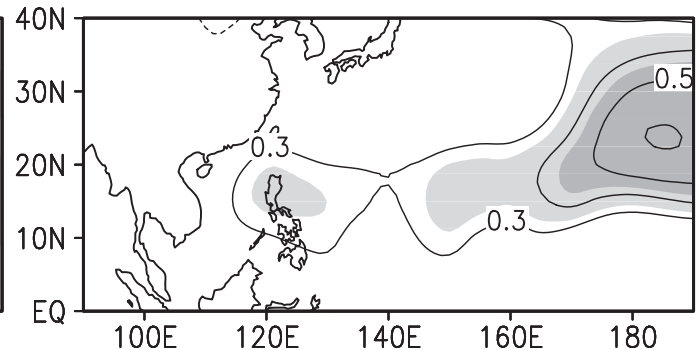

(h) Corr (Oct SLP \& TIO SSTA)

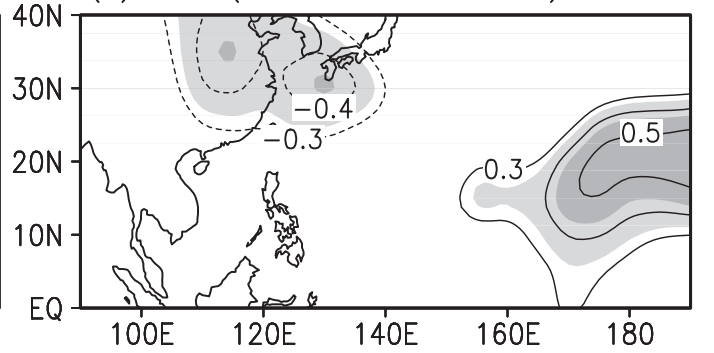

Fig. 6. Correlations of monthly SLP from July to October with the normalized Niño-3.4 index (left panels) and TIO SSTA index (right panels) averaged over JASO. Shadings indicate that correlation coefficients are statistically significant above $95 \%$ confidence level.

genesis. The index includes absolute vorticity, relative humidity, wind shear, and the potential intensity (PI; Emanuel 1988), which is derived from the SLP, SST, air temperature, and mixing ratio (Bister and Emanuel 2002). To clearly present the modulation of back- ground fields to TC genesis, the absolute vorticity is calculated using the TC-removed reanalysis data. Figure 7 shows the composite monthly GPI anomaly and suggests that the GPI anomaly mainly appears between $10^{\circ} \mathrm{N}$ and $20^{\circ} \mathrm{N}$ over JASO in the EDC mode. 

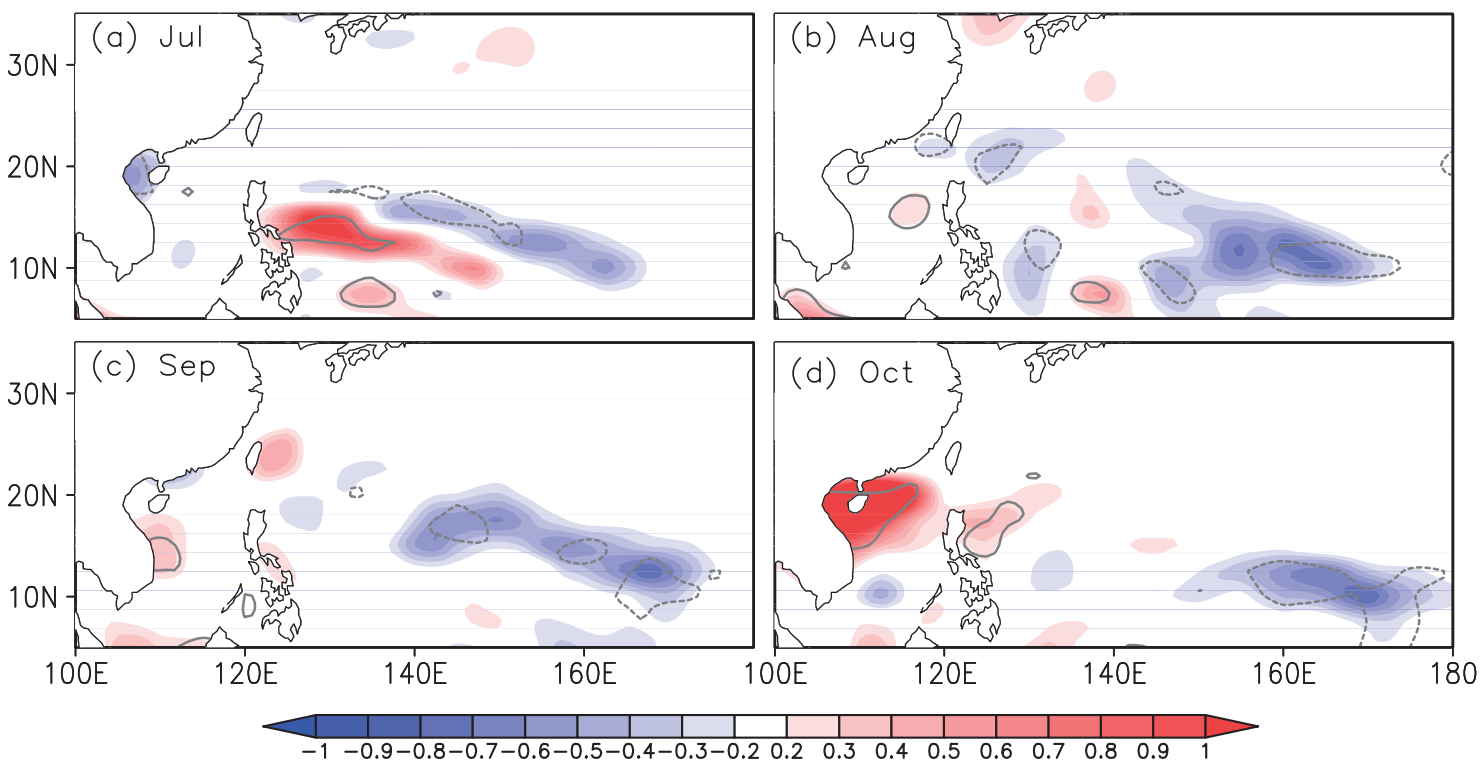

Fig. 7. Composite GPI anomaly (shade) in (a) July, (b) August, (c) September, and (d) October in the EDC mode. Regions enclosed by solid (dashed) contours indicate areas where the positive (negative) differences are significant at the $95 \%$ confidence level by the Student's $t$-test.

By comparing the TCGF and GPI anomalies, it is found that, just like the feature of negative TCGF anomaly (Fig. 1), the negative GPI anomaly also exhibits an eastward shift from July to October in the EDC mode, which implies that anomalous environmental conditions suppress TC genesis in the centraleastern WNP and modulate the longitudinal march of negative TCGF anomaly. In contrast, the positive GPI anomaly does not show the eastward shift feature, probably related to the exclusion of positive TC vorticity from the reanalysis wind field.

\section{Conclusions and discussion}

Recent studies have revealed that the TCGF significantly decreases over the WNP in the EDC years (Du et al. 2011; Zhan et al. 2011a, b; Tao et al. 2012). In this study, we focus on the longitudinal evolution of TCGF anomaly over the WNP from July to October under the influences of large-scale circulation and environmental conditions in the EDC mode. The main conclusions are as follows. TCGF exhibits a dipole pattern with a negative anomaly in the eastern WNP and a positive anomaly in the western WNP in EDC years. Both the negative and positive TCGF anomalies shift eastward from July to October, showing a longitudinal evolution feature. In particular, the averaged center of negative TCGF anomaly propa- gates eastward from $130^{\circ} \mathrm{E}$ in July to $160^{\circ} \mathrm{E}$ in midOctober, and the positive anomalous center shifts from $120^{\circ} \mathrm{E}$ in July to $145^{\circ} \mathrm{E}$ in October. In addition, the evolution of negative TCGF anomaly appears more evident than that of the positive. This evolution significantly affects distribution of climatological TC intensity over JASO in the EDC mode. Accordingly, the eastward shift of negative and positive TCKE anomalies is greatly attributed to the eastward movement of TCGF anomalies in summer, and the extensive negative TCKE anomaly dominates the entire WNP in the EDC fall. Moreover, the significant negative TCKE anomaly exhibits eastward propagation in mid-September and early October. It is found that the eastward shift of the WNP anomalous anticyclone, which is jointly modulated by the equatorial central eastern Pacific cooling and TIO warming, is responsible for the evolution of the TCGF anomaly. Moreover, the upper circulation anomaly shows the similar eastward shift feature corresponding to the lower troposphere. The variation of the GPI anomaly supports that the anomalous environmental conditions suppress TC genesis in the eastern WNP and further modulate the longitudinal evolution of TCGF anomaly over JASO in the EDC mode.

Besides the EDC mode, the EDV mode is a dominant interannual variability mode of the East 

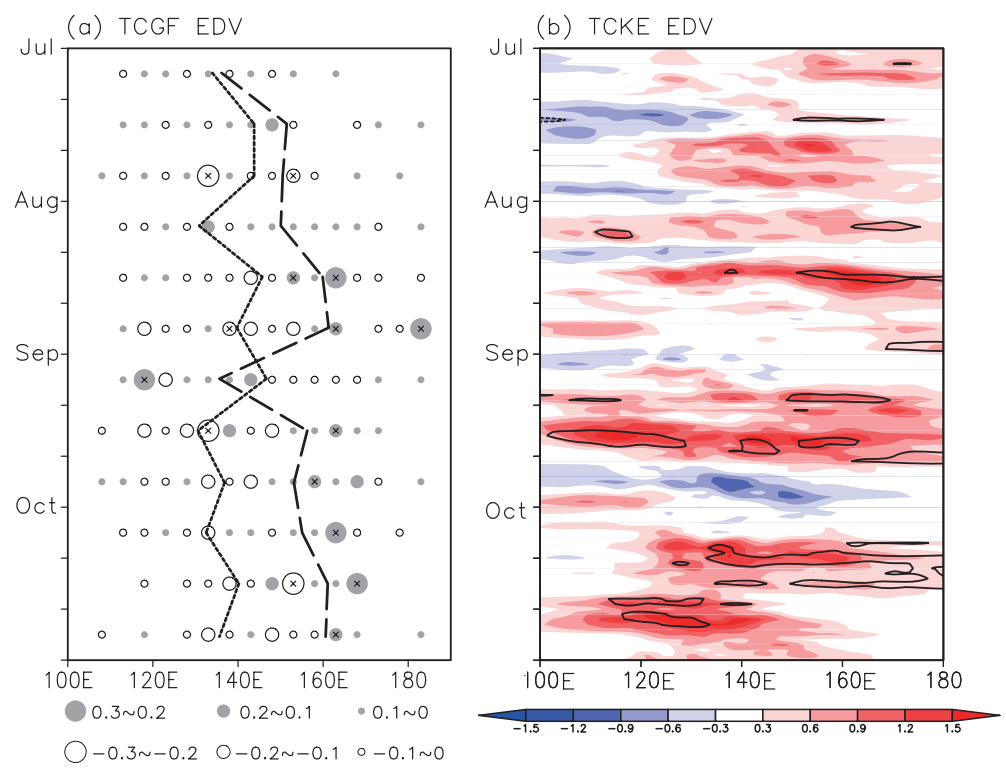

Fig. 8. Composite time-longitude cross section of (a) TCGF and (b) TCKE (shade; $\mathrm{m}^{2} \mathrm{~s}^{-2}$ ) anomalies in the EDV mode averaged between $0^{\circ}$ and $40^{\circ} \mathrm{N}$. Long (short) dashed line in (a) indicates mean longitudes of the positive (negative) TCGF anomaly. Circles with crosses in (a) and regions enclosed by solid (dashed) contours in (b) indicate that the positive (negative) differences are significant at the $95 \%$ confidence level by the Student's $t$-test.

Asian climate (Wu et al. 2010). It has been revealed that TC activity shows dipole pattern with a higher (lower) genesis frequency in the southeastern (northwestern) WNP during El Niño events (Chan 2000; Chia and Ropelewski 2002; Wang and Chan 2002; Camargo and Sobel 2005; Chen et al. 2006; Yang and Jiang 2008; Zhan et al. 2011a). Does the TCGF anomaly in the EDV mode show longitudinal evolution that is similar to that in the EDC mode? To answer this question, we examined the evolution of the WNP TCGF anomaly over JASO in the composite EDV year. Figure 8 shows the time-longitude cross section of anomalous TCGF and TCKE in the EDV mode averaged between $0^{\circ}$ and $40^{\circ} \mathrm{N}$. In general, the monthly TCs are higher from July to September, but slightly lower in October, than the respective monthly climatological means, and positive (negative) TCGF anomaly mainly concentrates in the eastern (western) WNP. Moreover, the positive center of TCGF anomaly exhibits an eastward shift from $140^{\circ} \mathrm{E}$ in July to $160^{\circ} \mathrm{E}$ in October (Fig. 8a), suggesting that the main TC genesis location exhibits an eastward shift in El Niño relative to the climatological mean. In contrast, the negative TCGF anomaly is mainly localized between $135^{\circ} \mathrm{E}$ and $145^{\circ} \mathrm{E}$, with indistinct longitudinal propagation over JASO. Although the significant negative
TCGF anomaly appears in the western WNP and the total TCGF over the entire WNP changes little relative to the neutral ENSO phases, the positive TCKE dominates the entire WNP and persists through October (Fig. 8b). This is because more TCs formed in the eastern WNP would be intensified as moving northward and westward over the ocean to reach intense TCs. This result also quantitatively explains and extends the understanding of the enhanced TC intensity in warm years (Wang and Chan 2002; Camargo and Sobel 2005; Chen et al. 2006). In general, the TCGF anomaly exhibits the opposite pattern between the EDC and EDV modes; in particular, the evolution of TCGF anomaly in the two modes shows different evolving variation from July to October, leading to the distinct distribution of TCKE anomaly to a great extent. In addition, although the correlation analysis suggests that the eastward shift of TCGF anomaly over the WNP is influenced by the equatorial central eastern Pacific cooling and TIO heating synergistically in the EDC years, under the influence of the TIO warming, the relative contribution of the equatorial central eastern Pacific cooling to the WNP TC activity in the EDC mode needs further study. 


\section{Acknowledgments}

This work is jointly sponsored by National Key Basic Research Program of China (2013CB956203), the R\&D Special Fund for Public Welfare Industry (Meteorology) (GYHY201306025), and National Natural Science Foundation of China (41175090).

\section{References}

Bister, M., and K. A. Emanuel, 2002: Low frequency variability of tropical cyclone potential intensity. 1. Interannual to interdecadal variability. J. Geophys. Res., 107, 4801, doi:10.1029/2001JD000776.

Camargo, S. J., and A. H. Sobel, 2005: Western North Pacific tropical cyclone intensity and ENSO. J. Climate, 18, 2996-3006.

Camargo, S. J., K. A. Emanuel, and A. H. Sobel, 2007: Use of a genesis potential index to diagnose ENSO effects on tropical cyclone genesis. J. Climate, 20, 4819-4834.

Chang, C. P., Y. S. Zhang, and T. Li, 2000a: Interannual and interdecadal variations of the East Asian summer monsoon and tropical Pacific SSTs. Part I: Roles of the subtropical ridge. J. Climate, 13, 4310-4325.

Chang, C. P., Y. S. Zhang, and T. Li, 2000b: Interannual and interdecadal variations of the East Asian summer monsoon and tropical Pacific SSTs. Part II: Meridional structure of the monsoon. J. Climate, 13, 4326-4340.

Chan, J. C. L., 2000: Tropical cyclone activity over the western North Pacific associated with El Niño and La Niña events. J. Climate, 13, 2960-2972.

Chen, T. C., S. Y. Wang, and M. C. Yen, 2006: Interannual variation of the tropical cyclone activity over the western North Pacific. J. Climate, 19, 5709-5720.

Chia, H. H., and C. F. Ropelewski, 2002: The interannual variability in the genesis location of tropical cyclones in the Northwest Pacific. J. Climate, 15, 2934-2944.

Du, Y., L. Yang, and S.-P. Xie, 2011: Tropical Indian Ocean influence on Northwest Pacific tropical cyclones in summer following strong El Niño. J. Climate, 24, 315322.

Emanuel, K. A., 1988: The maximum intensity of hurricanes. J. Atmos. Sci., 45, 1143-1155.

Emanuel, K. A., and D. S. Nolan, 2004: Tropical cyclone activity and global climate. Preprints, 26th Conf. on Hurricanes and Tropical Meteorology, Amer. Meteor. Soc., Miami, FL, 240-241.

Ha, Y., and Z. Zhong, 2013: Contrast of tropical cyclone frequency in the western North Pacific between two types of La Niña events. Science China Earth Sciences, 56, 397-407.

Ha, Y., Z. Zhong, Y. Hu, and X. Yang, 2013: Influences of ENSO on western North Pacific tropical cyclone kinetic energy and its meridional transport. J. Climate, 26, 322332.

He, P., and J. Jiang, 2011: Effect of PDO on the relationships between large scale circulation and tropical cyclone activity over the western North Pacific. J. Meteor. Sinica, 266-273.

Ho, C.-H., J.-J. Baik, J.-H. Kim, D.-Y. Gong, and C.-H. Sui, 2004: Interdecadal changes in summertime typhoon tracks. J. Climate, 17, 1767-1776.

Hsu, H.-H., C.-H. Hung, A.-K. Lo, C.-C. Wu, and C.-W. Hung, 2008: Influence of tropical cyclones on the estimation of climate variability in the tropical western North Pacific. J. Climate, 21, 2960-2975.

Japan Meteorological Agency, 2012: Regional Specialized Meteorological Center of Japan Meteorological Agency TC best-track data site. [Available at http://www.jma. go.jp/jma/jma-eng/jma-center/rsmc-hp-pub-eg/RSMC_ HP.htm.]

Ju, J., and J. M. Slingo, 1995: The Asian summer monsoon and ENSO. Quart. J. Roy. Meteor. Soc., 121, 1133-1168.

Kalnay, E., and co-authors, 1996: The NCEP/NCAR 40-year reanalysis project. Bull. Amer. Meteor. Soc., 77, 437471.

Klein, S. A., B. J. Soden, and N. C. Lau, 1999: Remote sea surface temperature variations during ENSO: Evidence for a tropical atmospheric bridge. J. Climate, 12, 917932.

Lander, M. A., 1994: An exploratory analysis of the relationship between tropical storm formation in the western North Pacific and ENSO. Mon. Wea. Rev., 122, 636-651.

Low-Nam, S., and C. Davis, 2001: Development of a tropical cyclone bogussing scheme for the MM5 System. Proc. 11th PSU/NCAR Mesoscale Model Users Workshop, National Center for Atmospheric Research, Boulder, $\mathrm{CO}, 130-134$. [Available at http://www.mmm.ucar. edu/mm5/workshop/ws01/lownam.pdf.]

Smith, T. M., R. W. Reynolds, T. C. Peterson, and J. Lawrimore, 2008: Improvements to NOAA's historical merged land-ocean surface temperature analysis (18802006). J. Climate, 21, 2283-2296.

Tao, L., L. Wu, Y. Wang, and J. Yang, 2012: Influence of tropical Indian Ocean warming and ENSO on tropical cyclone activity over the western North Pacific. $J$. Meteor. Soc. Japan, 90, 127-144.

Walsh, K. J. E., and B. F. Ryan, 2000: Tropical cyclone intensity increase near Australia as a result of climate change. J. Climate, 13, 3029-3036.

Walsh, K. J. E., M. Fiorino, C. Landsea, and K. McInnes, 2007: Objectively determined resolution-dependent threshold criteria for the detection of tropical cyclones in climate models and reanalyses. J. Climate, 20, 23072314 .

Wang, B., and J. C. L. Chan, 2002: How strong ENSO events affect tropical storm activity over the western North Pacific. J. Climate, 15, 1643-1658.

Wang, B., R. G. Wu, and X. H. Fu, 2000: Pacific-East Asian teleconnection: How does ENSO affect East Asian climate? J. Climate, 13, 1517-1536. 
Wang, B., and Q. Zhang, 2002: Pacific-east Asian teleconnection. Part II: How the Philippine Sea anomalous anticyclone is established during El Niño development? J. Climate, 15, 3252-3265.

Wu, B., T. J. Zhou, and T. Li, 2009: Seasonally evolving dominant interannual variability modes of East Asian climate. J. Climate, 22, 2992-3005.

Wu, B., T. Li, and T. J. Zhou, 2010: Relative contributions of the Indian Ocean and local SST anomalies to the maintenance of the western North Pacific anomalous anticyclone during the El Niño decaying summer. $J$. Climate, 23, 2974-2986.

Wu, L., 2007: Impact of Saharan air layer on hurricane peak intensity. Geophys. Res. Lett., 34, L09802, doi: 10.1029/2007GL029564.

Wu, L., B. Wang, and S. Geng, 2005: Growing typhoon influence on East Asia. Geophys. Res. Lett., 32, L18703, doi:10.1029/2005GL022937.

Wu, L., Z. Wen, R. Huang, and R. Wu, 2011: Possible linkage between the monsoon trough variability and the tropical cyclone activity over the western North Pacific. Mon. Wea. Rev., 140, 140-150.

Xie, S.-P., and S. G. H. Philander, 1994: A coupled oceanatmosphere model of relevance to the ITCZ in the eastern Pacific. Tellus A, 46, 340-350.

Xie, S.-P., K. Hu, J. Hafner, H. Tokinaga, Y. Du, G. Huang, and T. Sampe, 2009: Indian Ocean capacitor effect on Indo-western Pacific climate during the summer following El Niño. J. Climate, 22, 730-747.

Yang, J., Q. Liu, S.-P. Xie, Z. Liu, and L. Wu, 2007: Impact of the Indian Ocean SST basin mode on the Asian summer monsoon. Geophys. Res. Lett., 34, L02708, doi:10.1029/ 2006 GL028571.

Yang, Y., and J. Jiang, 2008: The impacts of sea surface temperature anomaly in the equatorial central and eastern Pacific on tropical cyclone in north-west Pacific. Scientia Meteor. Sinica, 28, 637-643 (in Chinese).
Yu, R., and T. J. Zhou, 2007: Seasonality and threedimensional structure of the interdecadal change in the East Asian monsoon. J. Climate, 20, 5344-5355.

Yuan, Y., S. Yang, and Z. Zhang, 2012: Different evolutions of the Philippine Sea anticyclone between Eastern and Central Pacific El Niño: Possible effect of Indian Ocean SST. J. Climate, 25, 7867-7883.

Zhan, R.-F., Y. Wang, and X. T. Lei, $2011 \mathrm{a}$ : Contributions of ENSO and East Indian Ocean SSTA to the interannual variability of Northwest Pacific tropical cyclone frequency. J. Climate, 24, 509-521.

Zhan, R.-F., Y. Wang, and C. C. Wu, 2011 b: Impact of SSTA in East Indian Ocean on the frequency of Northwest Pacific tropical cyclones: A regional atmospheric model study. J. Climate, 24, 6227-6242.

Zhan, R.-F., Y. Wang, and M. Wen, 2013: The SST gradient between the Southwest Pacific and the western Pacific warm pool-A new factor controlling the Northwest Pacific tropical cyclone genesis frequency. J. Climate, 26, 2408-2415.

Zhao, H., L. Wu, and W. Zhou, 2010: Assessing the influence of the ENSO on tropical cyclone prevailing tracks in the western North Pacific. Adv. Atmos. Sci., 27, 1361-1371.

Zhao, H., L. Wu, and W. Zhou, 2011: Interannual changes of tropical cyclone intensity in the western North Pacific. $J$. Meteor. Soc. Japan, 89, 245-255.

Zhou, T. J., and R. Yu, 2005: Atmospheric water vapor transport associated with typical anomalous summer rainfall patterns in China. J. Geophys. Res., 110, D08104, doi:10.1029/2004JD005413.

Zhou, T. J., and co-authors, 2009: The CLIVAR C20C Project: Which components of the Asian-Australian monsoon circulation variations are forced and reproducible? Climate Dyn., 33, 1051-1068.

Zhong. Z., and Y. Hu, 2007: Impacts of tropical cyclones on the regional climate: An East Asian summer monsoon case. Atmos. Sci. Lett., 8, 93-99. 